\title{
Enhancing M currents: a way out for neuropathic pain?
}

\author{
Ivan Rivera-Arconada, Carolina Roza and Jose A. Lopez-Garcia*
}

Departamento de Fisiología, Edificio de Medicina, Universidad de Alcala, Madrid, Spain

Edited by:

Bernard Attali, Tel Aviv University, Israel

Reviewed by:

Holger Lerche, Universitätsklinikum

UIm, Germany

Dirk Isbrandt, Zentrum für Molekulare

Neurobiologie Hamburg, Germany

*Correspondence:

Jose A. Lopez-Garcia, Departamento

de Fisiología, Edificio de Medicina

Universidad de Alcala, Alcala de

Henares, 28871 Madrid, Spain.

e-mail: josea.lopez@uah.es

\begin{abstract}
Almost three decades ago, the $\mathrm{M}$ current was identified and characterized in frog sympathetic neurons (Brown and Adams, 1980). The years following this discovery have seen a huge progress in the understanding of the function and the pharmacology of this current as well as on the structure of the underlying ion channels. Therapies for a number of syndromes involving abnormal levels of excitability in neurons are benefiting from research on $\mathrm{M}$ currents. At present, the potential of $\mathrm{M}$ current openers as analgesics for neuropathic pain is under discussion. Here we offer a critical view of existing data on the involvement of $M$ currents in pain processing. We believe that enhancement of $\mathrm{M}$ currents at the site of injury may become a powerful strategy to alleviate pain in some peripheral neuropathies.
\end{abstract}

Keywords: potassium current, KCNO, Kv7, pain, analgesia, pain therapy, neuropathy

\section{INTRODUCTION}

Potassium channels constitute a very wide family of ionic channels that are present in most biological entities. Individual subunits can combine to form heteromeric channels and post-transcriptional modifications of these subunits are possible yielding a great variety of potassium currents. Genetic defects in genes coding potassium channel subunits have been related to human diseases indicating the great importance that they have in cellular and systems physiology (Kullmann, 2002).

In excitable cells potassium channels are responsible for the control and regulation of excitability. The activity of individual potassium channels or combinations of them can determine resting potential, membrane resistance, action potential shape and firing adaptation. In addition, the antinociceptive action of several endogenous mediators like opioids as well as some anesthetics, are partly mediated by actions on potassium channels (Ocana et al., 2004). For these reasons, there is an increasing interest in studying the involvement of potassium channels in the sensitization of nociceptive systems (Hu et al., 2006).

M currents $\left(I_{\mathrm{M}}\right)$ and the underlying KCNQ or Kv7 channels have been related to several channelopathies that involve hyperexcitability in neurons of various areas of the nervous system. These include benign neonatal epilepsy and other forms of epilepsy, myokymia and peripheral nerve excitability (Maljevic et al., 2008). Several cues suggest that opening of $\mathrm{M}$ currents with specific anticonvulsants may be a valid target for analgesia in neuropathic pain states. In first place, anticonvulsants with different mechanisms of action like pregabalin and gabapentin are being successfully used for neuropathic pain therapy. In second place, basic research is providing evidence showing abundant expression of functional $M$ currents in primary afferents and the spinal cord, both key elements for nociceptive processing. Finally, some M current modulators are showing promising signs of pain relieve in animal models of neuropathic pain.

Here we review experimental work that has contributed to define $\mathrm{M}$ currents, to assess their presence and function in nociceptive systems and to evaluate their potential as targets for analgesia under conditions of neuropathy.

\section{CURRENTS: FUNCTION AND MODULATION}

In 1998, the molecular substrates for the M current were first identified as KCNQ2 and KCNQ3 channels (Wang et al., 1998) and later on, KCNQ4 and KCNQ5 were also found to contribute to generate M currents (Kubisch et al., 1999; Lerche et al., 2000; Schroeder et al., 2000). The remaining member of the family, KCNQ1, is heavily expressed in the heart but not in nervous system (Jentsch, 2000; Robbins, 2001). The present nomenclature for ion channels has renamed them as Kv7.1, Kv7.2, Kv7.3, Kv7.4 and Kv7.5 respectively and we will use this nomenclature from here onwards (Gutman et al., 2003).

Functional Kv7 channels require homomeric or heteromeric assemblies of four subunits. However, only the Kv7.3 subunit is able to form heteromeric channels with other members of the family (for review see Robbins, 2001). Kv7 proteins consist of six transmembrane domains and their structure has been studied in detail (Jentsch, 2000). Several sites of functional relevance have been described including phosphorylation sites (Schroeder et al., 1998; Surti et al., 2005), a calmodulin-binding site (Etxeberria et al., 2008; Yus-Najera et al., 2002) and binding sites for AKAP and ankyrinG (Hoshi et al., 2003; Pan et al., 2006). The general functions of these channels in the nervous system have been recently reviewed elsewhere (Brown and Passmore, 2009).

\section{CURRENT AND NEURONAL EXCITABILITY}

As expected from the various combinations of proteins that can form functional currents, there is not a single $\mathrm{M}$ current but rather a family of them that share some major traits. The classical $I_{\mathrm{M}}$ is a voltage dependent non-inactivating potassium current with a slow activation process which starts at membrane potentials close to rest (Brown and Yu, 2000). Molecular variations affect channel conductance and the sensitivity to modulators (Robbins, 2001). 
Because of its low activation threshold, it can contribute to maintain the resting potential together with other conductances (Lamas et al., 2002). At resting membrane potential there are very few operative ionic currents and therefore a large membrane resistance. In these conditions, although Kv7 channels are only starting to open, the small currents generated may have a large impact on resting potential. In agreement with this theoretical interpretation, modulation of Kv7 channels has been reported to produce changes in resting membrane potentials and/or input resistance in many neuronal types (Brown and Adams, 1980; Koyama and Appel, 2006; Lawrence et al., 2006; Lechner et al., 2003; Murase et al., 1986; Nowak and Macdonald, 1982, 1983a,b; Otto et al., 2002; Passmore et al., 2003; Rivera-Arconada and Lopez-Garcia, 2005; Romero et al., 2004; Wladyka and Kunze, 2006; Yue and Yaari, 2004). As a consequence of the effects on resting potential, Kv7 channels (particularly those containing Kv7.2 subunits) have been implicated in the modulation of neurotransmitter release (Lechner et al., 2003; Luisi et al., 2009; Martire et al., 2004, 2007).

$\mathrm{M}$ currents are active at potentials below the threshold for action potential initiation and tend to increase rapidly in magnitude with depolarization. This creates a force opposing to depolarization, delaying or precluding the firing of action potentials due to synaptic activation. Because the current does not inactivate but remains active during prolonged periods of depolarization it tends to reduce firing frequency. Modulation of Kv7 channels has an important impact on neuronal excitability as reported for many native neurons. Block of Kv7 channels leads to a decrease in rheobase and a reduction in the spike frequency adaptation reducing the interspike interval, while channel opening facilitation tends to produce opposite effects (Filippov et al., 2006; Hetka et al., 1999; Koyama and Appel, 2006; Lawrence et al., 2006; Lechner et al., 2003; Nowak and Macdonald, 1983a; Otto et al., 2002; Passmore et al., 2003; Peretz et al., 2005; Rivera-Arconada and Lopez-Garcia, 2005; Wladyka and Kunze, 2006; Yue and Yaari, 2004), but not always (Miles et al., 2005; Romero et al., 2004).

\section{ENDOGENOUS MODULATION OF M CURRENTS}

Kv7 channels are modulated by a variety of endogenous compounds like neurotransmitters and peptides via the activation of intracellular cascades of second messengers. Interestingly, most modulators produce a reduction of $I_{\mathrm{M}}$ and hence tend to increase the excitability of the neurons affected (Brown and Yu, 2000).

Activation of muscarinic acetylcholine receptors was the first pathway reported for $M$ current modulation and the name of the current is related to this fact (Brown and Adams, 1980). Cholinergic inhibition of $I_{\mathrm{M}}$ is a widespread mechanism and it has been confirmed in many areas of the nervous system including human cortical neurons (McCormick and Williamson, 1989). Cholinergic suppression of the current seems to be mediated by M1 receptors in most neuronal types tested (Marrion et al., 1989; Romero et al., 2004; Selyanko et al., 2000; Shen et al., 2005) but not in all of them (Rouse et al., 2000). The effect of muscarinic receptors on $I_{\mathrm{M}}$ seems to be mediated by G-proteins of the Gq or G11 class (Caulfield et al., 1994). In addition, it has been shown that PIP2 is a necessary cofactor for Kv7 function and that activation of muscarinic receptors produces PIP2 depletion (Suh and Hille, 2005).
Bradykinin has been shown to increase the excitability of SCG neurons inhibiting Kv7. This effect of bradykinin is mediated by $\mathrm{B} 2$ receptors and the activation of $\mathrm{G}$ alpha $\mathrm{q} / 11$ proteins acting via phospholipase C (Cruzblanca et al., 1998; Jones et al., 1995). This, in turn may cause increases in calcium concentration and closure of Kv7 channels (Brown et al., 2007; Delmas et al., 2002).

Several other endogenous mediators like serotonin and nerve growth factor have been implicated in $I_{\mathrm{M}}$ reduction (Jia et al., 2008; McCormick and Williamson, 1989). Similarly, activation of CB1 cannabinoid receptors (Schweitzer, 2000), P2Y purinergic receptors (Adams et al., 1982; Filippov et al., 2006; Zaika et al., 2007) and metabotropic glutamate receptors (Charpak et al., 1990) may reduce $\mathrm{M}$ currents.

In contrast to these excitatory effects mediated by $I_{M}$ depression, opioids and somatostatin have been reported to reduce neuronal excitability by potentiating the current. Activation of kappa receptors by modulators like dynorphin and nociceptin has been shown to depress the excitability of CA1 neurons (Madamba et al., 1999a,b; Moore et al., 1994). In this region of the CNS, somatostatin (and corticostatin) has been shown to augment the M current (de Lecea et al., 1996; Moore et al., 1988) activating the subtype 4 receptor (Qiu et al.,2008) and a subsequent pathway implicating arachidonic acid metabolites (Schweitzer et al., 1990). In neurons of the solitary tract somatostatin produces hyperpolarization and depresses excitability increasing Kv7 currents (Jacquin et al., 1988).

With the exception of muscarine and substance $\mathrm{P}$, there is no evidence that the other mentioned receptors and endogenous modulators may act on $\mathrm{M}$ currents to regulate pain processing. Of special interest in our context is the recent work performed on small diameter dorsal root ganglion cells (presumed nociceptors) showing that activation of Mas-related gene receptor D and protease-activated receptor 2 cause inhibition of $M$ currents and an abnormal excitability in nociceptive pathways which may be related to the origin of naturally occurring hyperalgesia after inflammation (Crozier et al., 2007; Linley et al., 2008).

\section{EXOGENOUS MODULATORS OF M CURRENTS}

Selective agonists and antagonists are extremely useful tools to evaluate the roles of ion channels and receptors at the systems level. The first compounds known to act as $M$ current modulators with a certain degree of potency and selectivity were linopirdine (channel blocker) and retigabine (channel opener). Although Kv7 channels are sensitive to tetraethylammonium (Hadley et al., 2000) this compound is not selective and blocks a variety of other potassium conductances. Linopirdine probably exerts its effect on Kv7 channels at the external side of the membrane (Costa and Brown, 1997). Important residues for the effect of retigabine on Kv7 channels are located within the pore region (Lange et al., 2009; Schenzer et al., 2005; Wuttke et al., 2005).

Linopirdine [3,3-bis(4-pyridinylmethyl)-1-phenylindolin-2one, DUP996] was described as a cognition enhancer that increases stimulus evoked neurotransmitter release in hippocampus without altering basal release. For this reason, it was proposed for the treatment of Alzheimer's disease (Tam and Zaczek, 1995). The mechanism of action of linopirdine is mostly mediated by Kv7 channel closure (Aiken et al., 1995), although effects on other potassium channels and receptors cannot be excluded (Lamas et al., 1997; 
Schnee and Brown, 1998). Some analogs of linopirdine show similar properties (Zaczek et al., 1998). Among them XE991 [10,10-bis(4pyridinylmethyl)-9(10H)-anthracenone] has been widely used for Kv7 channel studies because it has greater affinity and selectivity values than linopirdine for native M currents (Robbins, 2001; Schroder et al., 2001; Wang et al., 1998). These compounds also block cardiac Kv7.1 channels at low concentrations, however in native cardiac cells Kv7.1 associates with other accessory subunits that render the resulting current less sensitive to XE991 (Wang et al., 2000).

Kv7 channel blockers have been widely used for the identification of $\mathrm{M}$ currents in several neuronal types. In many neurons including dorsal root ganglion and spinal cord neurons, application of XE991 produces depolarization and an increase in the firing frequency to depolarizing stimuli (Aiken et al., 1995; Alaburda et al., 2002; Lawrence et al., 2006; Otto et al., 2002, 2006; Passmore et al., 2003; Peters et al., 2005; Rivera-Arconada and Lopez-Garcia, 2005; Wladyka and Kunze, 2006; Yue and Yaari, 2004). However some neurons show weak responses to XE991 even if they have Kv7 channels (Miles et al., 2005; Rivera-Arconada and Lopez-Garcia, 2005; Romero et al., 2004). This may be due to the subunit composition of the different channels or to the expression of other dominant currents in the same neuron. In many studies, Kv7 channel blockers have been used as antagonist to test the specificity of retigabine on M currents (Blackburn-Munro and Jensen, 2003; Dost et al., 2004; Passmore et al., 2003; Rivera-Arconada and Lopez-Garcia, 2005, 2006; Rivera-Arconada et al., 2004; Roza and Lopez-Garcia, 2008; Yue and Yaari, 2004).

Retigabine [D23129, ethylN-(2-amino-4-(4-fluorobenzylamino)phenyl] activates $\mathrm{M}$ currents produced by heterologous expression of Kv7.2/3 (Main et al., 2000; Rundfeldt and Netzer, 2000b; Wickenden et al., 2000). At concentrations between 0.1 and $10-\mu \mathrm{M}$ retigabine modifies the voltage dependence of these channels, increases the activation rate, slows its inactivation and favors the open channel configuration (Tatulian and Brown, 2003). Interestingly retigabine does not affect currents mediated by Kv7.1 channels. At larger concentrations, retigabine has been found to interact with GABA-ergic systems in some studies (Kapetanovic et al., 1995; Otto et al., 2002; Rundfeldt and Netzer, 2000a; van Rijn and Willems-van Bree, 2003) but not in others (Hetka et al., 1999).

Application of retigabine produces hyperpolarization and promotes spike frequency adaptation in several neuronal types including spinal cord neurons (Rivera-Arconada and Lopez-Garcia, 2005), dorsal root ganglion (Passmore et al., 2003), cortical (Hetka et al., 1999; Otto et al., 2002) and hippocampal neurons (Yue and Yaari, 2004). Retigabine also produces a reduction in neurotransmitter release induced by depolarization in synaptosomes (Luisi et al., 2009; Martire et al., 2004, 2007).

Due to their interesting and promising pharmacological properties, new Kv7 channel openers have been developed recently and Kv7 channel opener properties have been reported in existing compounds. Among these are flupirtine, BMS-204352, diclofenac, ICA-27243, several acrylamides and Zinc pyrithione (Dalby-Brown et al., 2006, Xiong et al., 2008). Diclofenac and meclofenamic acid are commonly used anti-inflammatory drugs which activate Kv7 channels (Peretz et al., 2005). The design of new derivates that maintain Kv7 enhancing properties without cyclooxygenase activity may lead to obtain potent and subunit specific Kv7 modulators that could be applicable to pain treatment (Peretz et al., 2007).

\section{Kv7 CHANNELS AND M CURRENTS IN SENSORY AFFERENTS}

Primary afferents are highly specialized elements of sensory systems comprising four differentiated domains with specialized functions, i.e., peripheral nerve endings, conducting axons, central terminals and cell bodies. Ion channels are distributed in an orderly and inhomogeneous form in each domain contributing in a decisive way to the signaling properties of individual fibers. Alterations in the quantitative expression or the orderly distribution of ion channels induced by injury may have profound effects in these signaling properties. The paragraphs bellow describe the experimental evidence supporting the presence of Kv7 channels in afferents and the functional consequences that may derive.

\section{PERIPHERAL NERVE ENDINGS}

Peripheral terminals contain the machinery required for transduction and coding of external stimuli. Several potassium conductances contribute to shape receptor potentials and to modulate coding properties of individual afferents (Belmonte and Viana, 2008). Several lines of evidence suggest the presence of Kv7 channels or the existence of $\mathrm{M}$ currents at specialized receptor endings (Barnes, 1994; Buniel et al., 2008). Wladyka et al. (2008) studied the sensory terminals of arterial baroreceptors and found expression of Kv7.2/3/5 channel subunits as well as modulation of pressureresponse relations by retigabine and XE991. These results indicate that Kv7 channels are likely contributors to coding process, at least in certain receptors.

Cutaneous sensitivity has been explored using the skin-nerve preparation by several groups. We found that only a small proportion of $\mathrm{A}_{\delta}$ and $\mathrm{C}$ afferent fibers responding to mechanical or chemical stimuli were responsive to XE991 and none of them responded to retigabine (Roza and Lopez-Garcia, 2008). We concluded that even if present in intact terminals, $M$ currents must have a minor role at coding of acute nociceptive stimuli of cutaneous origin. In agreement with this observation, cutaneous application of XE991 to live mice did not produce mechanical or thermal hyperalgesia (Linley et al., 2008). However, preliminary data from another group using the skin-nerve preparation (Passmore and Brown, 2007) reported a depressant action of retigabine on noxious heat and mechanical responses. It is possible that differences between these two data sets were due to the use of different animals (mice and rats respectively) or different types of sensory neurons, but further clarification will be required.

\section{CONDUCTING AXONS}

Conduction of action potentials through myelinated and unmyelinated axons involves two separated sets of mechanisms. At present, no data exist on the distribution and function of Kv7 channels along unmyelinated axons although electrophysiological experiments suggest the expression of functional $\mathrm{M}$ currents in this fiber type. In myelinated fibers, nodes of Ranvier at periodical interruptions of the myelin sheath enable saltatory conduction. Nodes are highly specialized structures enriched in sodium and potassium channels (Poliak and Peles, 2003). It has been shown that Kv7.2 channels are 
expressed in nodes of peripheral axons colocalized with sodium channels where they share an ankyrin-G-based mechanism of retention (Devaux et al., 2004; Pan et al., 2006). The Kv7.3 subunit has also been detected in paranodes and Schmidt-Lanterman incisures in a relative small percentage of fibers. It is noteworthy that Kv7.2 and Kv7.3 do not colocalize even when they are found in the same fibers. Therefore, it is likely that Kv7.2 homomers constitute the major contribution of Kv7 channels to nodal potassium currents, at least in peripheral fibers.

A variety of nodal and perinodal potassium channels may contribute to limit spike duration and frequency adaptation. Recently, Kv7.2 channels have been proposed to mediate the IKs (Schwarz et al., 2006), a slow potassium current previously detected at nodes (Dubois, 1981). XE991 has been shown to block IKs in single sciatic myelinated axons from rats maintained in vitro, the functional consequences being a decreased current threshold and a reduced adaptation to intracellular current pulses. Schwarz et al. (2006) showed that under in vivo conditions XE991 increase the excitability of motor axons. Accordingly, myokymia (neuromyotonia) has been described in connection with mutations affecting gating of Kv7.2 (Dedek et al., 2001; Wuttke et al., 2007). It is not known how this may relate to sensory conduction under physiological conditions although no sensory deficits have been associated to mutations in genes coding Kv7 channels.

\section{CENTRAL TERMINALS OF PRIMARY AFFERENTS}

Central terminals are specialized in the release of neurotransmitters onto second order dorsal horn neurons. Neurotransmitter release can be dynamically controlled by presynaptic contacts and local membrane potential. In addition, it has been proposed that excessive depolarization at central terminals may induce backfiring in the afferents contributing to peripheral sensitization (Willis, 1999). Therefore, the control of membrane potential and excitability at this point is crucial for sensory transmission.

Indirect electrophysiological observations on populations of afferent fibers indicate that functional Kv7/M currents are present in central terminals as well (Rivera-Arconada and Lopez-Garcia, 2006). Retigabine produces hyperpolarization of terminals and reduces the excitability of a range of afferent fibers including myelinated and unmyelinated afferents. XE991 has no effect on the terminals when applied alone but blocks the effects of retigabine.

\section{DORSAL ROOT GANGLION CELLS}

The cell bodies of primary afferents are grouped in dorsal root ganglia. The function of this compartment of primary afferents is not as clear as for the other components which are directly involved in the transmission of information from the periphery to the spinal cord. Action potential invasion of the soma is not required for transmission along the main process and there are no synapses in dorsal root ganglion. Somas of primary afferents are classically viewed as metabolic factories dedicated to supporting the conducting axon. However, the cell soma is normally invaded by action potentials running in the main process and this may represent some functional advantages (Amir and Devor, 2003).

Among a variety of sodium and potassium ion channels which confer the membrane full active electrical properties, the somata of dorsal root ganglion cells express Kv7 channels (Linley et al.,
2008; Passmore et al., 2003). Functional M currents with standard biophysics and pharmacological characteristics were found in large and small cells, some of them sensitive to capsaicin and therefore potential nociceptive fibers. Immunofluorescent analysis showed that Kv7.2/3/5 subunits were present in ganglion cells probably producing functional channels of all possible combinations. Modulation of $\mathrm{M}$ currents in dorsal root ganglion cells has been suggested as a mechanism to induce hyperexcitability during inflammation (Linley et al., 2008).

\section{CURRENTS, AFFERENT FIBERS AND NEUROPATHY}

Afferent fibers are known to play a fundamental role in the origin and maintenance of neuropathic states. After injury, a percentage of myelinated and unmyelinated afferents may degenerate and die. The surviving afferents may regenerate and innervate new targets or fail to regenerate and form a neuroma (Lisney, 1989). In the area of damage, fibers lose their myelin sheath and express a variety of membrane proteins such as transductors, receptors and ion channels normally not present in axons (Zimmermann, 2001). As a result these areas acquire the capacity to generate ectopic action potentials either spontaneously or in response to stimuli of different modalities. Similarly, axotomized dorsal root ganglion cells develop hyperexcitability and spontaneous activity (Amir et al., 2005).

Sodium channels are key elements for electrogenesis and a large number of observations indicate that they play an essential role in the development of ectopic activity (Devor, 2006). A role for potassium channels in ectopia has been anticipated on the basis of large increases in spontaneous activity produced by classic potassium channel blockers such as 4-aminopyridine and tetraethylammonium (Devor, 1983). Recent work indicates that Kv7 channels may influence hyperexcitability of neuromatose fibers. We used saphenous skin-nerve and nerve-end neuroma preparations to compare the effects of retigabine and XE991 on the coding properties of intact and neuromatose nerve endings (Roza and LopezGarcia, 2008). To our surprise, retigabine was devoid of effect on responses of intact $\mathrm{A}_{\delta}$ and $\mathrm{C}$-fibers to the stimulation of their receptive field. However responses of neuromatose $\mathrm{A}_{\delta}$ and $\mathrm{C}$-fibers where completely blunted by retigabine. In addition, XE991 blocked the inhibitory effect of retigabine. Mechanistic studies indicated that retigabine hyperpolarized the areas of ectopic discharge generation decreasing the probability of firing action potentials. This mechanism could operate to suppress activity independently of the nature of the stimulus and fiber type. These findings suggest that Kv7 channels gain an extraordinary important role in the control of ectopic discharges which may result from a complex rearrangement of the ion channels expressed at ectopic areas and/or an altered expression of Kv7 subunits as suggested by preliminary work (Wickenden et al., 2002). A similar conclusion may be reached from work on isolated fibers from human beings suffering from peripheral vascular disease or polyneuropathy (Lang et al., 2008). This altered sensitivity to retigabine in neuromatose fibers generates a peripheral target of interest for analgesia in some forms of neuropathy.

\section{Kv7 CHANNELS AND M CURRENTS IN THE SPINAL CORD}

The spinal cord receives sensory inputs from the periphery becoming the first relay center for nociceptive information. The spinal cord processes the original sensory messages integrating descending 
signals from the brain in order to produce two main forms of output: (1) sensory output to inform brain centers which eventually will generate the sensation of pain and (2) motor output to organize reflex activity. Whereas sensory outputs are generated in the dorsal horn, the motor output necessarily requires further processing in the ventral horn (Willis and Coggeshall, 2004). In this strategic position, the spinal cord is the structure most frequently studied to understand central mechanisms of pain processing.

Recently several studies have examined the expression of Kv7 subunits in the spinal cord although unfortunately a systematic description of the laminar distribution is not available yet. Despite the first failed attempts to detect the presence of Kv7 channels (Biervert et al., 1998; Smith et al., 2001; Yang et al., 1998), Dedek et al. (2001) demonstrated the presence of Kv7.2 and Kv7.3 subunits in both the dorsal and ventral horn of the mouse spinal cord using in situ hybridization which was later confirmed by immunoblots and immunohistochemical techniques (Devaux et al., 2004). These authors showed the presence of Kv7.2 channels in axon initial segments throughout the gray matter. The Kv7.3 subunit was also found in the gray matter of the spinal cord associated to axon initial segments and nodes of motoneurons (Pan et al., 2006). The presence of Kv7 subunits in axon initial segments confers a great relevance to Kv7 channels in the neuronal integration of synaptic inputs since this region of the axon constitutes a subcellular location of great importance in the generation of action potentials (Stuart et al., 1997). In addition, Kv7.3 channels may be expressed by astrocytes (Devaux et al., 2004).

Unpublished observations from our laboratory indicate that Kv7.5 subunits are also abundantly expressed in spinal cord neurons. We have used two different antisera previously used for immunohistochemical detection of Kv7.5 channels in nervous tissue (Caminos et al., 2007; Yus-Najera et al., 2003) and obtained the same picture: clear staining of a considerable proportion of dorsal horn (deep and superficial) and ventral horn neurons (inter- and motorneurons) as well as diffuse staining restricted to superficial dorsal areas that could label the central terminals of afferent fibers. The existence of Kv7.5 proteins in spinal cord neurons favors the possibility of producing heteromeric channels and adding functional and pharmacological diversity to spinal M currents.

\section{CURRENTS IN DORSAL HORN NEURONS}

The presence of M-like currents sensitive to muscarine and substance P modulation was first reported in cultured spinal neurons using electrophysiological techniques (Nowak and Macdonald, 1982, 1983a,b). Then, functional M-like currents were reported in Laminae II-IV dorsal horn neurons (Murase et al., 1986). More recently, retigabine was shown to produce significant dose-related inhibition of extracellular responses recorded from dorsal horn neurons in an in vivo rat preparation (Passmore et al., 2003). In this study, retigabine potently suppressed nociceptive processing and "wind up" in response to electrical stimuli. Wind-up consists of a progressive increment of spike counts in response to repetitive stimulation but only when nociceptive afferents are activated (Herrero et al., 2000). We confirmed these results in an in vitro preparation of the rat spinal cord and showed that XE991 produced opposite effects and blocked the effects of retigabine (RiveraArconada et al., 2004). With intracellular recordings, we observed that retigabine produces hyperpolarization of dorsal horn neurons and a decrease in their intrinsic excitability which manifests as an augmented rheobase and an increased spike frequency adaptation. XE991 produced a complete reversion of retigabine effects indicating a specific action on Kv7 channels; however, XE991 had a very weak excitatory effect when applied on its own (RiveraArconada and Lopez-Garcia, 2005). Interestingly, all studies show a large proportion of dorsal horn neurons responding to retigabine suggesting that Kv7 channels are commonly expressed by dorsal horn neurons.

\section{CURRENTS IN MOTONEURONS}

The presence of Kv7 at axon initial segments of motoneurons (Devaux et al., 2004; Pan et al., 2006), a structure of great importance in the generation and the transmission of action potentials, strongly argue in favor of a decisive role of these channels at regulating the motor output of the spinal cord. Electrophysiological studies using $\mathrm{M}$ current modulators also indicate the presence of functional $\mathrm{M}$ currents in spinal motoneurons regulating its intrinsic excitability. In turtle motoneurons both muscarine and XE991 increased the firing frequency of action potentials by reducing an M-like current (Alaburda et al., 2002). Retigabine has been shown to depress nociceptive spinal reflexes having only minor effects on non-nociceptive reflexes (Rivera-Arconada et al., 2004). As in the dorsal horn, retigabine reduces responses to the activation of nociceptive afferents and wind-up. Motoneurons show a similar response to retigabine as that reported for dorsal horn neurons, i.e., a decrease in excitability. However, XE991 produced extraordinary large increases in excitability compared to the effects seen in dorsal horn neurons. This could be due to a differential expression of Kv7 subunits in both neuronal types. Here again the effects of retigabine were prevented by XE991 coapplication indicating a selective action of the modulators on Kv7 channels. All motoneurons respond readily to the modulators, indicating a widespread expression of the channels (Rivera-Arconada and Lopez-Garcia, 2005).

\section{CURRENTS, THE SPINAL CORD AND NEUROPATHY}

There is abundant evidence supporting the concept of central sensitization (Ji et al., 2003). Although spinal neurons (and neurons in other brain centers related to pain processing) are not directly affected by a peripheral injury, they and the circuits they form become hyperexcitable amplifying subsequent afferent input abnormally. There is only one published study trying to evaluate possible changes in spinal Kv7 channel function as a consequence of peripheral neuropathy (Passmore et al., 2003). This electrophysiological study examined the responses of dorsal horn neurons to electrical and natural stimulation in rats that had undergone an experimental neuropathy. The authors showed that retigabine produced similar depressant actions on the excitability of neurons in both naïve and treated animals. These results suggest that spinal expression of Kv7 channels is maintained after peripheral injury and that these channels are still capable to influence excitability under the new conditions.

In agreement with the previous results, unpublished observations from our laboratory indicate that Kv7.5 expression in the spinal cord is not essentially altered by peripheral nerve injury. The only apparent change is an increase in the percentage of superficial 
dorsal horn neurons expressing Kv7.5. An increase of functional $M$ currents would contribute to stabilize neurons rather than to make them more excitable and therefore, if anything, this may be a homeostatic reaction to compensate for other sources of excitability.

Altogether, the data indicate that Kv7 channels are still present in the spinal cord after neuropathy and may become valuable targets for the control of neuronal excitability even in conditions of chronic pain and sensitization of the spinal cord.

\section{CURRENT MODULATION IN BEHAVIORAL MODELS OF NEUROPATHIC PAIN}

Neuropathic pain patients develop multiple and complex symptoms likely reflecting a variety of underlying physiopathological mechanisms. However, it is generally admitted that neuropathic conditions involve damage to peripheral or central components of the nociceptive system leading to hyperexcitability of the system itself. In peripheral nerves, spontaneous ectopic activity (attributed to redistribution of $\mathrm{K}^{+}$and $\mathrm{Na}^{+}$channels, Devor et al., 1993; Rasband et al., 2001) is related to positive symptoms of neuropathy (Bostock et al., 2005; Devor, 2006; Ochoa et al., 2005; Orstavik et al., 2003). Hence, anticonvulsant/antiepileptic drugs such as gabapentin and pregabalin have become an important option to treat neuropathic pain. Unfortunately, none of these drugs are 100\% effective and their use is often associated with limiting and adverse side effects (Sindrup and Jensen, 1999); consequently, the search for novel therapeutic targets is still compelling.

The channel opener retigabine has been proven effective in various seizure models (Wuttke and Lerche, 2006) and it is in phase III clinical testing to treat pharmaco-resistant focal epilepsies at present (Bialer et al., 2009). Since Kv7 channel openers can increase the stability of peripheral and central components of the nociceptive system, they are potential targets of interest for neuropathic pain. While there is a large body of experimental data on the effects of anticonvulsant drugs in the treatment of neuropathic pain (Blackburn-Munro and Erichsen, 2005), there is still sparse and at times puzzling data on the outcome of Kv7 modulation in this scenario. Data with new Kv7 channel openers on models of neuropathic pain (like ICA-27243, flupirtine or acrylamide) has been published only in abstract form (see Wickenden et al., 2004 for a review) and only two full papers have been published with original data on the effects of retigabine on models of neuropathy (Blackburn-Munro and Jensen, 2003; Dost et al., 2004). Retigabine has been tested in three different models: spinal nerve ligation (SNL, Kim and Chung, 1992), chronic constriction injury (CCI, Bennett and Xie, 1988) and spared nerve injury (SNI, Decosterd and Woolf, 2000). The SNL model involves the ligation or sectioning of a dorsal root, the CCI model uses loose ligatures around the sciatic nerve and the SNI model sections the tibial and common peroneal branches of the sciatic nerve leaving the sural nerve intact. All three models have in common the fact that they produce a partial nerve injury leaving extensive skin areas supplied by intact fibers and therefore responsive to natural stimulation. Upon stimulation of these areas, allodynia and hyperalgesia are commonly observed. A feature that may differentiate between the models is the contribution of intact and damaged fibers to the observed symptoms (Campbell and Meyer, 2006).
Oral administration of retigabine to SNL rats reduced signs of mechanical allodynia (measured as threshold for paw withdrawal). In this case, retigabine was more potent than gabapentin (Dost et al., 2004). This reduction was dose-dependent and reversed by co-administration of linopirdine indicating a specific action on Kv7 channels. In these experiments, retigabine also reduced signs of heat hyperalgesia (measured as withdrawal latency to a heat source) although reversal experiments were not performed.

In a different experiment (Blackburn-Munro and Jensen, 2003), comparable oral doses of retigabine did not modify mechanical allodynia in CCI or SNI rats but reduced mechanical hyperalgesia (assessed as withdrawal time to a pin-prick stimulus). In addition, retigabine reduced cold allodynia (assessed as withdrawal time to application of an ethyl chloride spray) in CCI rats although reversal experiments were not reported. Unfortunately, this later effect was not observed in SNI rats. It is important to note that ataxic effects of retigabine appeared at doses about twofold greater than those required for their analgesic effects.

Other experiments have been performed with Kv7 openers using other pain models like intraplantar injection of capsaicin or formalin (Blackburn-Munro and Jensen, 2003; Passmore et al., 2003). In both experiments oral administration of retigabine reduced signs of pain and these effects were antagonized by co-administration of XE991. One more experiment has been performed using a model of muscular pain which involves intramuscular injections of acidic saline. In this case intraperitoneal administration of both retigabine and flupirtine were shown to reduce signs of pain (Nielsen et al., 2004).

Signs of cognitive distress or spontaneous pain may accompany neuropathic syndromes (Andersen and Tufik, 2003; Djouhri et al., 2006; LaBuda and Fuchs, 2000; Monassi et al., 2003; Pedersen and Blackburn-Munro, 2006). In this regard, retigabine has been shown to reduce anxiety in models of unconditioned anxiety but not in models of conditioned anxiety (Korsgaard et al., 2005; Munro and Dalby-Brown, 2007). Mood modulation could be an additional mechanism for Kv7 channel openers to improve neuropathic pain conditions.

The general outcome of behavioral experiments is that opening of Kv7 channels tends to reduce signs of pain in models of neuropathy. This is hopeful; however, more experiments will be required to clarify present discrepancies and to establish the pain conditions more susceptible to improve with retigabine and other Kv7 channel openers.

\section{CONCLUDING REMARKS}

Although we may be looking at early times of research on the viability of $\mathrm{M}$ current modulation as a strategy for pain therapy, an emerging body of interesting and promising data is already available. Unfortunately many questions remain unanswered.

It is now very clear that functional $M$ currents are present in primary afferents and spinal neurons, both key elements for nociceptive processing. In addition, they may be present in other areas related to pain processing. Are these channels involved in the generation or maintenance of sensitized states leading to lasting pain? On the basis of existing data, it seems possible that endogenous modulation of the $\mathrm{M}$ current in dorsal root ganglion cells contributes to make sensory fibers more excitable 
after peripheral inflammation (Crozier et al., 2007; Linley et al., 2008). However, this working hypothesis and its application to neuropathy will require further validation. On the other hand, there is no evidence supporting a contribution of spinal $\mathrm{M}$ currents to the initiation of central sensitization. A decreased expression of the channel or the functional current in the spinal cord could be interpreted as an active mechanism leading to increase the excitability of spinal neurons and therefore as a contribution towards maintaining spinal sensitization. Such decreased expression or function has not been found (see ' $M$ currents, the spinal cord and neuropathy').

Given this extensive expression of Kv7 channels in the nociceptive system which persists after injury, what is the interest of Kv7 channels as targets for neuropathic pain? The outcome of behavioral studies is scarce but positive. Data available so far indicate that potentiation of $\mathrm{M}$ currents tend to reduce signs of pain in neuropathic animals. Basic research on primary afferents suggests that the site of injury at the periphery may be a particularly interesting point for the action of modulators (Lang et al., 2008; Roza and Lopez-Garcia, 2008). Some forms of neuropathy

\section{REFERENCES}

Adams, P. R., Brown, D. A., and Constanti, A. (1982). Pharmacological inhibition of the M-current. J. Physiol. 332, 223-262.

Aiken, S.P., Lampe, B. J., Murphy, P.A., and Brown, B.S. (1995). Reduction of spike frequency adaptation and blockade of M-current in rat CA1 pyramidal neurones by linopirdine (DuP 996), a neurotransmitter release enhancer. Br. J. Pharmacol. 115, 1163-1168.

Alaburda, A., Perrier, J. F., and Hounsgaard, J. (2002). An M-like outward current regulates the excitability of spinal motoneurones in the adult turtle. J. Physiol. 540, 875-881.

Amir, R., and Devor, M. (2003). Electrical excitability of the soma of sensory neurons is required for spike invasion of the soma, but not for through-conduction. Biophys. J. 84, 2181-2191.

Amir, R., Kocsis, J. D., and Devor, M. (2005). Multiple interacting sites of ectopic spike electrogenesis in primary sensory neurons. J. Neurosci. 25, 2576-2585.

Andersen, M. L., and Tufik, S. (2003). Sleep patterns over 21-day period in rats with chronic constriction of sciatic nerve. Brain Res. 984, 84-92.

Barnes, S. (1994). After transduction: response shaping and control of transmission by ion channels of the photoreceptor inner segments. Neuroscience 58, 447-459.

Belmonte, C., and Viana, F. (2008). Molecular and cellular limits to somatosensory specificity. Mol. Pain 4, 14.

Bennett, G. J., and Xie, Y. K. (1988). A peripheral mononeuropathy in rat that produces disorders of pain may benefit from the development of Kv7 openers which do not cross the blood brain barrier or compounds for topical application that can be directly applied over the damaged nerves and be absorbed through the skin. Data from spinal cord research draws a much more complicated picture. $\mathrm{M}$ currents are present in most spinal neurons (sensory and motor) and other areas of the nervous system. Therefore, compounds designed to act at this level may show little selectivity for pain processing. A great amount of information will be required to refine centrally acting Kv7 openers. Key data in this process are detailed maps of the expression of individual Kv7 subunits by neurons of the nociceptive system and the development of subunit-specific openers. However, as with many other receptors and ion channels, there is no guarantee that a particular Kv7 subunit is central to pain processing during neuropathic pain.

\section{ACKNOWLEDGMENTS}

Authors are supported by the Spanish Ministry of Science and Education (Grant No. SAF 2006-03044) and the Local Government of Madrid (Grant No. S-SAL 0305-2006). sensation like those seen in man. Pain 33, 87-107.

Bialer, M., Johannessen, S. I., Levy, R. H., Perucca, E., Tomson, T., and White, H. S. (2009). Progress report on new antiepileptic drugs: a summary of the Ninth Eilat Conference (EILAT IX). Epilepsy Res. 83, 1-43.

Biervert, C., Schroeder, B. C., Kubisch, C., Berkovic, S. F., Propping, P., Jentsch, T. J., and Steinlein, O. K. (1998).A potassium channel mutation in neonatal human epilepsy. Science 279, 403-406.

Blackburn-Munro, G., and Erichsen, H. K. (2005). Antiepileptics and the treatment of neuropathic pain: evidence from animal models. Curr. Pharm. Des. 11, 2961-2976.

Blackburn-Munro, G., and Jensen, B. S. (2003). The anticonvulsant retigabine attenuates nociceptive behaviours in rat models of persistent and neuropathic pain. Eur. J. Pharmacol. 460, 109-116.

Bostock, H., Campero, M., Serra, J., and Ochoa, J. L. (2005). Temperaturedependent double spikes in C-nociceptors of neuropathic pain patients. Brain 128, 2154-2163.

Brown, B. S., and Yu, S. P. (2000). Modulation and genetic identification of the M channel. Prog. Biophys. Mol. Biol. 73, 135-166.

Brown, D. A., and Adams, P. R. (1980). Muscarinic suppression of a novel voltage-sensitive $\mathrm{K}+$ current in a vertebrate neurone. Nature 283, 673-676.

Brown, D. A., Hughes, S. A., Marsh, S. J., and Tinker, A. (2007). Regulation of $\mathrm{M}(\mathrm{Kv} 7.2 / 7.3)$ channels in neurons by PIP(2) and products of
PIP(2) hydrolysis: significance for receptor-mediated inhibition. J. Physiol. 582, 917-925.

Brown, D. A., and Passmore, G. M. (2009). Neural KCNQ (Kv7) channels. Br. J. Pharmacol. 156, 1185-1195.

Buniel, M., Glazebrook, P. A., RamirezNavarro, A., and Kunze, D. L. (2008) Distribution of voltage-gated potassium and hyperpolarization-activated channels in sensory afferent fibers in the rat carotid body. J. Comp. Neurol. 510, 367-377.

Caminos, E., Garcia-Pino, E., MartinezGalan, J. R., and Juiz, J. M. (2007). The potassium channel KCNQ5/Kv7.5 is localized in synaptic endings of auditory brainstem nuclei of the rat. J. Comp. Neurol. 505, 363-378.

Campbell, J. N., and Meyer, R. A. (2006) Mechanisms of neuropathic pain. Neuron 52, 77-92.

Caulfield, M. P., Jones, S., Vallis, Y., Buckley, N. J., Kim, G. D., Milligan, G., and Brown, D. A. (1994). Muscarinic M-current inhibition via $G$ alpha q/11 and alpha-adrenoceptor inhibition of $\mathrm{Ca} 2+$ current via $\mathrm{G}$ alpha o in rat sympathetic neurones. J. Physiol. 477(Pt 3), 415-422.

Charpak, S., Gahwiler, B. H., Do, K. Q. and Knopfel, T. (1990). Potassium conductances in hippocampal neurons blocked by excitatory amino-acid transmitters. Nature 347, 765-767.

Costa, A. M. N., and Brown, B. S. (1997). Inhibition of M-current in cultured rat superior cervical ganglia by linopirdine: mechanism of action studies. Neuropharmacology 36, 1747-1753.

Crozier, R. A., Ajit, S. K., Kaftan, E. J., and Pausch, M. H. (2007). MrgD activation inhibits KCNQ/M-currents and contributes to enhanced neuronal excitability. J. Neurosci. 27, 4492-4496.

Cruzblanca, H., Koh, D. S., and Hille, B. (1998). Bradykinin inhibits M current via phospholipase $\mathrm{C}$ and $\mathrm{Ca} 2+$ release from IP3-sensitive $\mathrm{Ca} 2+$ stores in rat sympathetic neurons. Proc. Natl. Acad. Sci. U.S.A. 95, 7151-7156.

Dalby-Brown, W., Hansen, H. H. Korsgaard, M. P., Mirza, N., and Olesen, S. P. (2006). K(v)7 channels: function, pharmacology and channel modulators. Curr. Top. Med. Chem. 6, 999-1023.

de Lecea, L., Criado, J. R., ProsperoGarcia, O., Gautvik, K. M., Schweitzer, P., Danielson, P. E., Dunlop, C. L., Siggins, G. R., Henriksen, S. J., and Sutcliffe, J. G. (1996). A cortical neuropeptide with neuronal depressant and sleepmodulating properties. Nature 381, 242-245.

Decosterd, I., and Woolf, C. J. (2000) Spared nerve injury: an animal model of persistent peripheral neuropathic pain. Pain 87, 149-158.

Dedek, K., Kunath, B., Kananura, C., Reuner, U., Jentsch, T. J., and Steinlein, O. K. (2001). Myokymia and neonatal epilepsy caused by a mutation in the voltage sensor of the KCNQ2 K+ channel. Proc. Natl. Acad. Sci. U.S.A. 98, 12272-12277.

Delmas, P., Wanaverbecq, N., Abogadie, F. C., Mistry, M., and Brown, D.A. (2002). Signaling microdomains define the specificity of receptor-mediated $\operatorname{Ins} \mathrm{P}(3)$ pathways in neurons. Neuron 34, 209-220. 
Devaux, J. J., Kleopa, K. A., Cooper, E. C., and Scherer, S. S. (2004). KCNQ2 is a nodal K+ channel. J. Neurosci. 24 1236-1244.

Devor, M. (1983). Potassium channels moderate ectopic excitability of nerveend neuromas in rats. Neurosci. Lett. 40, 181-186.

Devor, M. (2006). Sodium channels and mechanisms of neuropathic pain. J. Pain 7, S3-S12.

Devor, M., Govrin-Lippmann, R., and Angelides, K. (1993). Na+ channel immunolocalization in peripheral mammalian axons and changes following nerve injury and neuroma formation. J. Neurosci. 13, 1976-1992.

Djouhri, L., Koutsikou, S., Fang, X., McMullan, S., and Lawson, S. N. (2006). Spontaneous pain, both neuropathic and inflammatory, is related to frequency of spontaneous firing in intact C-fiber nociceptors. J. Neurosci. 26, 1281-1292.

Dost, R., Rostock, A., and Rundfeldt, C. (2004). The anti-hyperalgesic activity of retigabine is mediated by KCNQ potassium channel activation. Naunyn Schmiedebergs Arch. Pharmacol. 369, 382-390.

Dubois, J. M. (1981). Evidence for the existence of three types of potassium channels in the frog Ranvier node membrane. J. Physiol. 318, 297-316.

Etxeberria, A., Aivar, P., RodriguezAlfaro, J. A., Alaimo, A., Villace, P., Gomez-Posada, J. C., Areso, P., and Villarroel, A. (2008). Calmodulin regulates the trafficking of KCNQ2 potassium channels. FASEB J. 22, 1135-1143.

Filippov, A. K., Choi, R. C., Simon, J., Barnard, E. A., and Brown, D. A. (2006). Activation of P2Y1 nucleotide receptors induces inhibition of the $\mathrm{M}$ type $\mathrm{K}+$ current in rat hippocampal pyramidal neurons. J. Neurosci. 26, 9340-9348.

Gutman, G. A., Chandy, K. G., Adelman, J. P., Aiyar, J., Bayliss, D. A., Clapham, D. E., Covarriubias, M., Desir, G. V., Furuichi, K., Ganetzky, B., Garcia, M. L., Grissmer, S., Jan, L. Y., Karschin,A., Kim,D., Kuperschmidt, S., Kurachi, Y., Lazdunski, M., Lesage, F., Lester, H. A., McKinnon, D., Nichols, C. G., O’Kelly, I., Robbins, J., Robertson, G. A., Rudy, B., Sanguinetti, M., Seino, S., Stuehmer, W., Tamkun, M. M., Vandenberg, C. A., Wei, A., Wulff, H., Wymore, R. S., and International Union of Pharmacology. (2003). International Union of Pharmacology. XLI. Compendium of voltage-gated ion channels: potassium channels. Pharmacol. Rev. 55, 583-586.
Hadley, J. K., Noda, M., Selyanko, A. A., Wood, I. C., Abogadie, F. C., and Brown, D. A. (2000). Differential tetraethylammonium sensitivity of KCNQ1-4 potassium channels. $\mathrm{Br}$. J. Pharmacol. 129, 413-415.

Herrero, J. F., Laird, J. M., and LopezGarcia, J. A. (2000). Wind-up of spinal cord neurones and pain sensation: much ado about something? Prog. Neurobiol. 61, 169-203.

Hetka, R., Rundfeldt, C., Heinemann, U., and Schmitz, D. (1999). Retigabine strongly reduces repetitive firing in rat entorhinal cortex. Eur. J. Pharmacol. 386, 165-171.

Hoshi, N., Zhang, J. S., Omaki, M., Takeuchi, T., Yokoyama, S., Wanaverbecq, N., Langeberg, L. K., Yoneda, Y., Scott, J. D., Brown, D. A., and Higashida, H. (2003). AKAP150 signaling complex promotes suppression of the M-current by muscarinic agonists. Nat. Neurosci. 6, 564-571.

Hu, H. J., Carrasquillo, Y., Karim, F., Jung, W. E., Nerbonne, J. M., Schwarz, T. L., and Gereau, R. W. IV. (2006). The kv4.2 potassium channel subunit is required for pain plasticity. Neuron 50, 89-100.

Jacquin, T., Champagnat, J., Madamba, S., Denavit-Saubie, M., and Siggins, G. R. (1988). Somatostatin depresses excitability in neurons of the solitary tract complex through hyperpolarization and augmentation of IM, a non-inactivating voltage-dependent outward current blocked by muscarinic agonists. Proc. Natl. Acad. Sci. U.S.A. 85, 948-952.

Jentsch, T. J. (2000). Neuronal KCNQ potassium channels: physiology and role in disease. Nat. Rev. Neurosci. 1, 21-30.

Ji, R., Kohno, T., Moore, K. A., and Woolf, C. J. (2003). Central sensitization and LTP: do pain and memory share similar mechanisms? Trends Neurosci. 26, 696-705.

Jia, Z., Bei, J., Rodat-Despoix, L., Liu, B., Jia, Q., Delmas, P., and Zhang, H. (2008). NGF inhibits M/KCNQ currents and selectively alters neuronal excitability in subsets of sympathetic neurons depending on their M/KCNQ current background. J. Gen. Physiol. 131, 575-587.

Jones, S., Brown, D. A., Milligan, G., Willer, E., Buckley, N. J., and Caulfield, M. P. (1995). Bradykinin excites rat sympathetic neurons by inhibition of $\mathrm{M}$ current through a mechanism involving $\mathrm{B} 2$ receptors and G alpha q/11. Neuron 14, 399-405.

Kapetanovic, I. M., Yonekawa, W. D., and Kupferberg, H. J. (1995). The effects of D-23129, a new experimental anticonvulsant drug, on neurotransmitter amino acids in the rat hippocampus in vitro. Epilepsy Res. 22, 167-173.

Kim, S. H., and Chung, J. M. (1992). An experimental model for peripheral neuropathy produced by segmental spinal nerve ligation in the rat. Pain 50, 355-363.

Korsgaard, M.P., Hartz, B.P., Brown, W. D. Ahring, P. K., Strobaek, D., and Mirza, N. R. (2005). Anxiolytic effects of Maxipost (BMS-204352) and retigabine via activation of neuronal Kv7 channels. J. Pharmacol. Exp. Ther. 314 282-292.

Koyama, S., and Appel, S. B. (2006) Characterization of M-current in ventral tegmental area dopamine neurons. J. Neurophysiol. 96, 535-543.

Kubisch, C., Schroeder, B. C., Friedrich, T., Lutjohann, B., El-Amraoui, A., Marlin, S., Petit, C., and Jentsch, T. J. (1999). KCNQ4, a novel potassium channel expressed in sensory outer hair cells, is mutated in dominant deafness. Cell 96, 437-446.

Kullmann, D. M. (2002). The neuronal channelopathies. Brain 125 1177-1195.

LaBuda, C. J., and Fuchs, P. N. (2000) A behavioral test paradigm to measure the aversive quality of inflammatory and neuropathic pain in rats. Exp. Neurol. 163, 490-494.

Lamas, J.A., Reboreda, A., and Codesido, V. (2002). Ionic basis of the resting membrane potential in cultured rat sympathetic neurons. Neuroreport 13, 585-591.

Lamas, J. A., Selyanko, A. A., and Brown, D. A. (1997). Effects of a cognition-enhancer, linopirdine (DuP 996), on M-type potassium currents (IK(M) ) and some other voltage- and ligand-gated membrane currents in rat sympathetic neurons. Eur. J. Neurosci. 9, 605-616.

Lang, P. M., Fleckenstein, J., Passmore, G. M., Brown, D. A., and Grafe,P. (2008). Retigabine reduces the excitability of unmyelinated peripheral human axons. Neuropharmacology 54, 1271-1278.

Lange, W., Geissendorfer, J., Schenzer, A., Grotzinger, J., Seebohm, G., Friedrich, T., and Schwake, M. (2009). Refinement of the binding site and mode of action of the anticonvulsant Retigabine on KCNQ K+ channels. Mol. Pharmacol. 75, 272-280.

Lawrence, J. J., Saraga, F., Churchill, J. F., Statland, J. M., Travis, K. E., Skinner, F. K., and McBain, C. J. (2006). Somatodendritic Kv7/KCNQ/M channels control interspike interval in hippocampal interneurons. J. Neurosci. 26, 12325-12338.

Lechner, S. G., Mayer, M., and Boehm, S. (2003). Activation of M1 muscarinic receptors triggers transmitter release from rat sympathetic neurons through an inhibition of M-type $\mathrm{K}+$ channels. J. Physiol. 553, 789-802.

Lerche, C., Scherer, C. R., Seebohm, G., Derst, C., Wei, A. D., Busch, A. E., and Steinmeyer, K. (2000). Molecular cloning and functional expression of KCNQ5, a potassium channel subunit that may contribute to neuronal Mcurrent diversity. J. Biol. Chem. 275, 22395-22400.

Linley, J. E., Rose, K., Patil, M., Robertson, B., Akopian, A. N., and Gamper, N. (2008). Inhibition of $\mathrm{M}$ current in sensory neurons by exogenous proteases: a signaling pathway mediating inflammatory nociception. J. Neurosci. 28, 11240-11249.

Lisney, S. J. (1989). Regeneration of unmyelinated axons after injury of mammalian peripheral nerve. Q. J. Exp. Physiol. 74, 757-784.

Luisi, R., Panza, E., Barrese, V., Iannotti, F. A., Viggiano, D., Secondo, A., Canzoniero, L. M., Martire, M., Annunziato, L., and Taglialatela, M. (2009). Activation of pre-synaptic M-type $\mathrm{K}+$ channels inhibits $[3 \mathrm{H}] \mathrm{D}$-aspartate release by reducing $\mathrm{Ca} 2+$ entry through $\mathrm{P} / \mathrm{Q}$ type voltage-gated $\mathrm{Ca} 2+$ channels. J. Neurochem. 109, 168-181.

Madamba, S. G., Schweitzer, P., and Siggins, G. R. (1999a). Dynorphin selectively augments the M-current in hippocampal CA1 neurons by an opiate receptor mechanism. J. Neurophysiol. 82, 1768-1775.

Madamba, S. G., Schweitzer, P., and Siggins, G. R. (1999b). Nociceptin augments $\mathrm{K}(+)$ currents in hippocampal CA1 neurons by both ORL-1 and opiate receptor mechanisms. J. Neurophysiol. 82, 1776-1785.

Main, M. J., Cryan, J. E., Dupere, J. R., Cox, B., Clare, J. J., and Burbidge, S. A. (2000). Modulation of KCNQ2/3 potassium channels by the novel anticonvulsant retigabine. Mol. Pharmacol. 58, 253-262.

Maljevic, S., Wuttke, T. V., and Lerche, H. (2008). Nervous system KV7 disorders: breakdown of a subthreshold brake. J. Physiol. 586, 1791-1801.

Marrion, N. V., Smart, T. G., Marsh, S. J. and Brown, D. A. (1989). Muscarinic suppression of the M-current in the rat sympathetic ganglion is mediated by receptors of the M1-subtype. $B r$. J. Pharmacol. 98, 557-573.

Martire, M., Castaldo, P., D’Amico, M., Preziosi, P., Annunziato, L., and Taglialatela, M. (2004). M channels containing KCNQ2 subunits modulate norepinephrine, aspartate, and GABA release from hippocampal nerve terminals. J. Neurosci. 24, 592-597. 
Martire, M., D’Amico, M., Panza, E., Miceli, F., Viggiano, D., Lavergata, F., Iannotti, F. A., Barrese, V., Preziosi, P., Annunziato, L., and Taglialatela, M. (2007). Involvement of KCNQ2 subunits in $[3 \mathrm{H}]$ dopamine release triggered by depolarization and presynaptic muscarinic receptor activation from rat striatal synaptosomes. J. Neurochem. 102, 179-193.

McCormick, D. A., and Williamson, A. (1989). Convergence and divergence of neurotransmitter action in human cerebral cortex. Proc. Natl. Acad. Sci. U.S.A. 86, 8098-8102.

Miles, G. B., Dai, Y., and Brownstone, R. M. (2005). Mechanisms underlying the early phase of spike frequency adaptation in mouse spinal motoneurones. J. Physiol. 566, 519-532.

Monassi, C. R., Bandler, R., and Keay, K. A. (2003). A subpopulation of rats show social and sleep-waking changes typical of chronic neuropathic pain following peripheral nerve injury. Eur. J. Neurosci. 17, 1907-1920.

Moore, S. D., Madamba, S. G., Joels, M., and Siggins, G. R. (1988). Somatostatin augments the M-current in hippocampal neurons. Science 239, 278-280.

Moore, S. D., Madamba, S. G., Schweitzer, P., and Siggins, G. R. (1994). Voltage-dependent effects of opioid peptides on hippocampal CA3 pyramidal neurons in vitro. J. Neurosci. 14, 809-820.

Munro, G., and Dalby-Brown, W. (2007). Kv7 (KCNQ) channel modulators and neuropathic pain. J. Med. Chem. 50, 2576-2582.

Murase, K., Ryu, P. D., and Randic, M. (1986). Substance P augments a persistent slow inward calcium-sensitive current in voltage-clamped spinal dorsal horn neurons of the rat. Brain Res. 365, 369-376.

Nielsen, A. N., Mathiesen, C., and Blackburn-Munro, G. (2004). Pharmacological characterisation of acid-induced muscle allodynia in rats. Eur. J. Pharmacol. 487, 93-103.

Nowak, L. M., and Macdonald, R. L. (1982). Substance P: ionic basis for depolarizing responses of mouse spinal cord neurons in cell culture. J. Neurosci. 2, 1119-1128.

Nowak, L. M., and Macdonald, R. L. (1983a). Ionic mechanism of muscarinic cholinergic depolarization of mouse spinal cord neurons in cell culture. J. Neurophysiol. 49, 792-803.

Nowak, L. M., and Macdonald, R. L. (1983b). Muscarine-sensitive voltage-dependent potassium current in cultured murine spinal cord neurons. Neurosci. Lett. 35, 85-91.

Ocana, M., Cendan, C. M., Cobos, E. J. Entrena, J. M., and Baeyens, J. M.
(2004). Potassium channels and pain: present realities and future opportunities. Eur. J. Pharmacol. 500, 203-219.

Ochoa, J. L., Campero, M., Serra, J., and Bostock, H. (2005). Hyperexcitable polymodal and insensitive nociceptors in painful human neuropathy. Muscle Nerve 32, 459-472.

Orstavik, K., Weidner, C., Schmidt, R., Schmelz, M., Hilliges, M., Jorum, E., Handwerker, H., and Torebjork, E. (2003). Pathological C-fibres in patients with a chronic painful condition. Brain 126, 567-578.

Otto, J.F., Kimball, M.M., andWilcox, K. S. (2002). Effects of the anticonvulsant retigabine on cultured cortical neurons: changes in electroresponsive properties and synaptic transmission. Mol. Pharmacol. 61, 921-927.

Otto, J. F., Yang, Y., Frankel, W. N., White, H. S., and Wilcox, K. S. (2006). A spontaneous mutation involving Kcnq2 (Kv7.2) reduces M-current density and spike frequency adaptation in mouse CA1 neurons. J. Neurosci. 26, 2053-2059.

Pan, Z., Kao, T., Horvath, Z., Lemos, J., Sul, J. Y., Cranstoun, S. D., Bennett, V., Scherer, S.S., and Cooper, E. C. (2006). A common ankyrin-G-based mechanism retains $\mathrm{KCNQ}$ and $\mathrm{NaV}$ channels at electrically active domains of the axon. J. Neurosci. 26, 2599-2613.

Passmore, G. M., and Brown, D.A. (2007). Effects of M-channel Modulators on Peripheral Excitability in Rat Hairy Skin. Program No. 681.8. 2007 Neuroscience Meeting Planner. San Diego, CA, Society for Neuroscience.

Passmore, G. M., Selyanko, A. A., Mistry, M., Al Qatari, M., Marsh, S. J., Matthews, E. A., Dickenson, A. H., Brown, T.A., Burbidge, S.A., Main, M., and Brown, D. A. (2003). KCNQ/M currents in sensory neurons: significance for pain therapy. J. Neurosci. 23, 7227-7236.

Pedersen, L. H., and Blackburn-Munro, G. (2006). Pharmacological characterisation of place escape/avoidance behaviour in the rat chronic constriction injury model of neuropathic pain. Psychopharmacology (Berl) 185, 208-217.

Peretz, A., Degani, N., Nachman, R., Uziyel, Y., Gibor, G., Shabat, D., and Attali, B. (2005). Meclofenamic acid and diclofenac, novel templates of KCNQ2/Q3 potassium channel openers, depress cortical neuron activity and exhibit anticonvulsant properties. Mol. Pharmacol. 67, 1053-1066.

Peretz,A., Degani-Katzav,N., Takmon, M., Danieli, E., Gopin, A., Malka, E., Nachman, R., Raz, A. Shabat, D., and Attali, B. (2007). A tale of switched functions: from cyclooxygenase inhibition to M-channels modulation in new diphenylamine derivatives PLoS One 12, e1132. doi: 10.1371/ journal.pone.0001332.

Peters, H.C., Hu, H., Pongs, O., Storm, J. F. and Isbrandt, D. (2005). Conditional transgenic suppression of $\mathrm{M}$ channels in mouse brain reveals functions in neuronal excitability, resonance and behavior. Nat. Neurosci. 8, 51-60.

Poliak, S., and Peles, E. (2003). The local differentiation of myelinated axons at nodes of Ranvier. Nat. Rev. Neurosci. 4, 968-980.

Qiu, C., Zeyda, T., Johnson, B. Hochgeschwender, U., de Lecea, L., and Tallent, M. K. (2008). Somatostatin receptor subtype 4 couples to the $\mathrm{M}$-current to regulate seizures. J. Neurosci. 28, 3567-3576.

Rasband, M. N., Park, E. W. Vanderah, T. W., Lai, J., Porreca, F., and Trimmer, J. S. (2001). Distinct potassium channels on pain-sensing neurons. Proc. Natl. Acad. Sci. U.S.A. 98, 13373-13378.

Rivera-Arconada, I., and LopezGarcia, J. A. (2005). Effects of M-current modulators on the excitability of immature rat spinal sensory and motor neurones. Eur. J. Neurosci. 22, 3091-3098.

Rivera-Arconada, I., and LopezGarcia, J. A. (2006). Retigabineinduced population primary afferent hyperpolarisation in vitro. Neuropharmacology 51, 756-763.

Rivera-Arconada, I., Martinez-Gomez, J. and Lopez-Garcia, J. A. (2004). M-current modulators alter rat spinal nociceptive transmission: an electrophysiological study in vitro. Neuropharmacology 46, 598-606.

Robbins, J. (2001). KCNQ potassium channels: physiology, pathophysiology, and pharmacology. Pharmacol. Ther. 90, 1-19.

Romero, M., Reboreda, A., Sanchez, E., and Lamas, J. A. (2004). Newly developed blockers of the M-current do not reduce spike frequency adaptation in cultured mouse sympathetic neurons. Eur. J. Neurosci. 19, 2693-2702.

Rouse, S. T., Hamilton, S. E., Potter, L. T., Nathanson, N. M., and Conn, P. J. (2000). Muscarinic-induced modulation of potassium conductances is unchanged in mouse hippocampal pyramidal cells that lack functional M1 receptors. Neurosci. Lett. 278, 61-64.

Roza, C., and Lopez-Garcia, J. A. (2008). Retigabine, the specific KCNQ channel opener, blocks ectopic discharges in axotomized sensory fibres. Pain 138 , 537-545.

Rundfeldt, C., and Netzer, R. (2000a). Investigations into the mechanism of action of the new anticonvulsant retigabine. Interaction with GABAergic and glutamatergic neurotransmission and with voltage gated ion channels. Arzneimittelforschung 50, 1063-1070.

Rundfeldt, C., and Netzer, R. (2000b). The novel anticonvulsant retigabine activates M-currents in Chinese hamster ovary-cells transfected with human KCNQ2/3 subunits. Neurosci. Lett. 282, 73-76.

Schenzer, A., Friedrich, T., Pusch, M., Saftig, P., Jentsch, T. J., Grotzinger, J., and Schwake, M. (2005). Molecular determinants of KCNQ (Kv7) K+ channel sensitivity to the anticonvulsant retigabine. J. Neurosci. 25, 5051-5060.

Schnee, M. E., and Brown, B. S. (1998). Selectivity of linopirdine (DuP 996), a neurotransmitter release enhancer, in blocking voltage-dependent and calcium-activated potassium currents in hippocampal neurons. J. Pharmacol. Exp. Ther. 286, 709-717.

Schroder, R. L., Jespersen, T., Christophersen, P., Strobaek,D., Jensen, B. S., and Olesen, S. P. (2001). KCNQ4 channel activation by BMS-204352 and retigabine. Neuropharmacology 40, 888-898.

Schroeder, B. C., Hechenberger, M., Weinreich, F., Kubisch, C., and Jentsch, T. J. (2000). KCNQ5, a novel potassium channel broadly expressed in brain, mediates M-type currents. J. Biol. Chem. 275, 24089-24095.

Schroeder, B. C., Kubisch, C., Stein, V., and Jentsch, T. J. (1998). Moderate loss of function of cyclic-AMP-modulated KCNQ2/KCNQ3 K+ channels causes epilepsy. Nature 396, 687-690.

Schwarz, J. R., Glassmeier, G., Cooper, E. C., Kao, T. C., Nodera, H., Tabuena, D., Kaji, R., and Bostock, H. (2006). KCNQ channels mediate IKs, a slow $\mathrm{K}+$ current regulating excitability in the rat node of Ranvier. J. Physiol. 573, 17-34.

Schweitzer, P. (2000). Cannabinoids decrease the $\mathrm{K}(+)$ M-current in hippocampal CA1 neurons. J. Neurosci. 20, 51-58.

Schweitzer, P., Madamba, S., and Siggins, G. R. (1990). Arachidonic acid metabolites as mediators of somatostatin-induced increase of neuronal M-current. Nature 346, 464-467.

Selyanko, A. A., Hadley, J. K., Wood, I. C., Abogadie, F. C., Jentsch, T. J., and Brown, D. A. (2000). Inhibition of KCNQ1-4 potassium channels expressed in mammalian cells via M1 muscarinic acetylcholine receptors. J. Physiol. 522(Pt 3), 349-355.

Shen, W., Hamilton, S. E., Nathanson, N. M., and Surmeier, D. J. (2005). Cholinergic suppression of KCNQ channel currents enhances 
excitability of striatal medium spiny neurons. J. Neurosci. 25, 7449-7458.

Sindrup, S. H., and Jensen, T. S. (1999). Efficacy of pharmacological treatments of neuropathic pain: an update and effect related to mechanism of drug action. Pain 83, 389-400.

Smith, J. S., Iannotti, C. A., Dargis, P., Christian, E. P., and Aiyar, J. (2001). Differential expression of kcnq2 splice variants: implications to $\mathrm{m}$ current function during neuronal development. J. Neurosci. 21, 1096-1103.

Stuart, G., Spruston, N., Sakmann, B., and Hausser, M. (1997). Action potential initiation and backpropagation in neurons of the mammalian CNS. Trends Neurosci. 20, 125-131.

Suh, B. C., and Hille, B. (2005). Regulation of ion channels by phosphatidylinositol 4,5-bisphosphate. Curr. Opin. Neurobiol. 15, 370-378.

Surti, T. S., Huang, L., Jan, Y. N., Jan, L. Y., and Cooper,E.C.(2005). Identification by mass spectrometry and functional characterization of two phosphorylation sites of KCNQ2/KCNQ3 channels. Proc. Natl. Acad. Sci. U.S.A. 102, 17828-17833.

Tam, S. W., and Zaczek, R. (1995). Linopirdine. A depolarization-activated releaser of transmitters for treatment of dementia. Adv. Exp. Med. Biol. 363, 47-56.

Tatulian, L., and Brown, D. A. (2003). Effect of the KCNQ potassium channel opener retigabine on single KCNQ2/3 channels expressed in $\mathrm{CHO}$ cells. J. Physiol. 549, 57-63.

van Rijn, C. M., and Willems-van Bree, E. (2003). Synergy between retigabine and GABA in modulating the convulsant site of the GABAA receptor complex. Eur. J. Pharmacol. 464, 95-100.

Wang, H. S., Brown, B. S., McKinnon, D., and Cohen, I. S. (2000). Molecular basis for differential sensitivity of
KCNQ and $\mathrm{I}(\mathrm{Ks})$ channels to the cognitive enhancer XE991. Mol. Pharmacol. 57, 1218-1223.

Wang, H. S., Pan, Z., Shi, W., Brown, B. S., Wymore, R. S., Cohen, I.S., Dixon, J. E., and McKinnon, D. (1998). KCNQ2 and KCNQ3 potassium channel subunits: molecular correlates of the M-channel. Science 282, 1890-1893.

Wickenden, A. D., Roeloffs, R., McNaughton-Smith, G., and Rigdon, G. C. (2004). KCNQ potassium channels: drug targets for the treatment of epilepsy and pain. Expert Opin. Ther. Pat. 14, 457-469.

Wickenden, A. D., Ye, F., McNaughtonSmith, G., Roeloffs, R., and Rigdon, G. C. (2002). KCNQ Channel Expression in Rat DRG Following Nerve Ligation. Program No. 454.7. 2002 Neuroscience Meeting Planner. Orlando, FL, Society for Neuroscience.

Wickenden, A. D., Yu, W., Zou, A., Jegla, T., and Wagoner, P. K. (2000). Retigabine, a novel anti-convulsant, enhances activation of $\mathrm{KCNQ} 2 / \mathrm{Q} 3$ potassium channels. Mol. Pharmacol. 58, 591-600.

Willis, W. D. Jr. (1999). Dorsal root potentials and dorsal root reflexes: a double-edged sword. Exp. Brain Res. 124, 395-421.

Willis, W. D. Jr., and Coggeshall, R. E. (2004). Sensory mechanisms of the spinal cord. New York, NY, Kluwer Academic/Plenum Publishers.

Wladyka, C. L., Feng, B., Glazebrook, P. A. Schild, J. H., and Kunze, D. L. (2008). The KCNQ/M-current modulates arterial baroreceptor function at the sensory terminal in rats. J. Physiol. 586, 795-802.

Wladyka, C. L., and Kunze, D. L. (2006). $\mathrm{KCNQ} / \mathrm{M}$-currents contribute to the resting membrane potential in rat visceral sensory neurons. J. Physiol. 575, 175-189.
Wuttke, T. V., Jurkat-Rott, K., Paulus, W. Garncarek, M., Lehmann-Horn, F. and Lerche, H. (2007). Peripheral nerve hyperexcitability due to dominant-negative KCNQ2 mutations. Neurology 69, 2045-2053.

Wuttke, T. V., and Lerche, H. (2006) Novel anticonvulsant drugs targeting voltage-dependent ion channels. Expert Opin. Investig. Drugs 15 1167-1177.

Wuttke, T. V., Seebohm, G., Bail, S. Maljevic, S., and Lerche, H. (2005). The new anticonvulsant retigabine favors voltage-dependent opening of the Kv7.2 (KCNQ2) channel by binding to its activation gate. $\mathrm{Mol}$. Pharmacol. 67, 1009-1017.

Xiong, Q., Gao, Z., Wang, W., and Li, M (2008). Activation of Kv7 (KCNQ) voltage-gated potassium channels by synthetic compounds. Trends Pharmacol. Sci. 29, 99-107.

Yang, W. P., Levesque, P. C., Little, W. A., Conder, M. L., Ramakrishnan, P. Neubauer, M. G., and Blanar, M. A (1998). Functional expression of two KvLQT1-related potassium channels responsible for an inherited idiopathic epilepsy. J. Biol. Chem. 273 , 19419-19423.

Yue, C., and Yaari, Y. (2004). KCNQ/M channels control spike afterdepolarization and burst generation in hippocampal neurons. J. Neurosci. 24 4614-4624.

Yus-Najera, E., Munoz, A., Salvador, N. Jensen, B. S., Rasmussen, H. B. Defelipe, J., and Villarroel, A. (2003). Localization of KCNQ5 in the normal and epileptic human temporal neocortex and hippocampal formation. Neuroscience 120, 353-364.

Yus-Najera, E., Santana-Castro, I., and Villarroel, A. (2002). The identification and characterization of a noncontinuous calmodulin-binding site in noninactivating voltage-dependent KCNQ potassium channels. J. Biol. Chem. 277, 28545-28553.

Zaczek, R., Chorvat, R. J., Saye, J. A., Pierdomenico, M. E., Maciag, C. M., Logue, A. R., Fisher, B. N. Rominger, D. H., and Earl, R. A. (1998). Two new potent neurotransmitter release enhancers, 10,10-bis(4-pyridinylmethyl)$9(10 \mathrm{H})$-anthracenone and 10,10-bis(2-fluoro-4-pyridinylmethyl)-9(10H)-anthracenone: comparison to linopirdine. J. Pharmacol. Exp. Ther. 285, 724-730.

Zaika, O., Tolstykh, G. P., Jaffe, D. B., and Shapiro, M. S. (2007). Inositol triphosphate-mediated $\mathrm{Ca} 2+$ signals direct purinergic $\mathrm{P} 2 \mathrm{Y}$ receptor regulation of neuronal ion channels. J. Neurosci. 27, 8914-8926.

Zimmermann, M. (2001). Pathobiology of neuropathic pain. Eur. J. Pharmacol. 429, 23-37.

Conflict of Interest Statement: Authors declare that the research was conducted in the absence of any commercial or financial relationships which could be construed as a potential conflict of interests.

Received: 16June 2009; paper pending published: 18 July 2009; accepted: 23 July 2009; published online: 04 August 2009.

Citation: Rivera-Arconada I, Roza C and Lopez-Garcia JA (2009) Enhancing $M$ currents: a way out for neuropathic pain? Front. Mol. Neurosci. 2:10. doi: 10.3389/neuro.02.010.2009

Copyright (c) 2009 Rivera-Arconada, Roza and Lopez-Garcia. This is an open-access article subject to an exclusive license agreement between the authors and the Frontiers Research Foundation, which permits unrestricted use, distribution, and reproduction in any medium, provided the original authors and source are credit. 